\title{
O Drama da EtNOgrafia ${ }^{1}$
}

\author{
Kate Donelan ${ }^{2}$
}

Etnografia é uma metodologia de pesquisa particularmente apropriada para o estudo do drama em contextos educacionais. Escrevi anteriormente sobre a afinidade entre drama e etnografia e as qualidades de empatia e identificação que são fundamentais ao trabalho do drama educador e do etnógrafo (Donelan, 1991, 1994). A capacidade de se projetar imaginariamente dentro de uma situação e se identificar com outra perspectiva possibilita que pessoas explorem a experiência humana no drama; possibilita que um professor de drama compreenda as experiências de seus alunos e isto permite ao etnógrafo observar a vida através dos olhos daqueles que ele está estudando. Neste artigo vou discutir alguns dos valores e processos que são compartilhados pelo etnógrafo e o professor de drama e meu entendimento dos respectivos desafios artísticos e emocionais que o etnógrafo enfrenta ao pesquisar a prática do drama. Dois estudos etnográficos em que estou envolvida atualmente, em comunidades escolares, fornecerão o contexto para esta discussão.

As conexões entre etnografia e drama na educação estão refletidas na linguagem, nas categorias conceituais e nas áreas de debate entre os dois campos de conhecimento. Por exemplo, há hoje uma preocupação com o relacionamento apropriado entre processo e produto na orientação do trabalho etnográfico (Van Maanen, 1995; Wolcott, 1995; Woods, 1996). Críticas da prática etnográfica focalizam as qualidades do produto pesquisado - o texto etnográfico e "o problema que as representações etnográficas atualmente enfrentam” (Van Maanen, 1995:15). Para Agar (in Van Maanen, 1995) etnografia é um termo ambíguo dado que ele se refere "tanto ao processo de pesquisa e a um produto textual” (p.112). Onde quer que 'novos' etnógrafos focalizem o texto etnográfico como distinto do trabalho de campo, ele propõe um inter-relacionamento

${ }^{1}$ Tradução de Biange Cabral, professora da Universidade do Estado de Santa Catarina. Texto publicado no livro Drama and Theatre in Education - International Conversations (eds. Carole Miller e Juliana Saxton. Canadá: International Drama in Education Institute.

${ }^{2}$ Senior Lecturer and Head of Drama. The University of Melbourne 
próximo entre textos etnográficos escritos "e os processos de pesquisa que os subsidiaram” (p.129). Entre os drama educadores a posição mudou do debate sobre se processo e produto estão separados e em oposição, para um consenso que eles são formas inter-relacionadas de prática artística e educacional contínuas, com o contex to determinando a orientação apropriada do trabalho do drama e do teatro (Fleming, 1994; O’Toole, 1992; Burton, 1991).

Outro tema relacionado com etnógrafos e drama educadores é o conceito de "artistry" (dimensão artística) e a medida pela qual os processos artísticos são inerentes à prática da pesquisa e do ensino. A recente análise de Taylor (1995) sobre o trabalho de dois eminentes drama educadores confirma que os aspectos estéticos e simbólicos estão embutidos dentro de todos os estágios do processo em drama. Em um livro recente, A Arte do Trabalho de Campo, Wolcott (1995) aponta um argumento convincente a favor das qualidades artísticas requeridas do etnógrafo tanto na condução da pesquisa em campo e na construção de seu registro. Wolcott reconhece que o processo de estudar o ser humano em um contexto particular de interações sociais, sempre será caracterizado por relacionamentos complexos em que nada ocorre exatamente da mesma forma duas vezes; entretanto, "o desafio artístico é preservar, divulgar, e celebrar aquela complexidade” (p.19).

Os estudos etnográficos de drama educação estão baseados na suposição de que a ação dramática pode somente ser entendida em termos do enquadramento dentro da qual ela ocorre e "do contexto e objetivos dos participantes" (O’Toole, 1992:2). O pesquisador precisa estar sintonizado com as qualidades particulares do contexto social e cultural e se engajar num processo de interpretação hermenêutica. É dada atenção aos detalhes de eventos e interações na medida em que elas ocorrem, como também à busca de conexões entre eventos e padrões, temas e significados. Um entendimento do texto social dos participantes e do texto teatral do drama emerge de forma dinâmica e cumulativa no decorrer das fases interconectadas do trabalho de campo, coleta de dados, análise e escrita (Donelan, 1994).

Em ambos meus estudos de drama, em andamento, eu estou tentando acessar, interpretar e descrever as experiências coletivas e individuais de estudantes e professores enquanto engajados na prática do drama dentro de seus ambientes educacionais particulares. Um desses estudos é parte de um projeto nacional em colaboração, e focaliza a prática do drama nas séries iniciais e o conceito de pré-texto (O’Neill, 1995). Professores das séries iniciais de cada Estado e Território da Austrália, planejaram, ensinaram e documentaram sessões de drama de três horas de duração baseadas em um pré-texto comum: Os Mistérios de Harris Burdick (Van Allsburg, 1984). Eu trabalhei como co- 
pesquisador com Tiina Moore (que está dirigindo o Projeto Pré-Texto nas Séries Iniciais) para apoiar seu estudo das sessões de drama que ela ministrou a uma turma de $4^{\mathrm{a}}$ série de sua escola. Como observadora passiva, sentada ao fundo de sua sala de drama, eu fui uma testemunha do drama gerado pelo prétexto; da minha perspectiva de outsider eu escrevi notas de observação de campo que complementaram outras fontes de dados. Nossas reflexões e análise das sessões de drama focalizaram o pensamento de Tïna e tomadas de decisão como professor/pesquisador, o engajamento dos estudantes nas várias fases do drama, momentos críticos que ocorreram e o relacionamento entre o pré-tex to e a ação dramática. Nós agora estamos construindo um relatório no qual a conclusão de Tiina, como professora e pesquisadora, irá incluir as vozes das crianças e minha recepção, cruzadas através de um relato em forma de diálogo reflexivo.

Em outro estudo, eu venho documentando um projeto de drama intercultural sendo desenvolvido por um artista/educador performático africano em uma escola secundária. Há cinco meses eu venho identificando o efeito deste projeto inovador na vida da comunidade escolar. Eu estou interessada na forma pela qual este projeto de drama e suas interfaces podem gerar conscientização cultural, engajamento estético e empoderamento pessoal e comunitário. Em contraste com o estudo anterior, eu adotei um papel ativo e participante de forma a me tornar um membro parcial da cultura da escola. Ao assumir tarefas dentro do projeto, eu compartilhei com os participantes os eventos criticamente e contribui para seus insights quanto à forma de responder ao projeto na medida em que este se desenvolvia. Atualmente, com o trabalho de campo em sua etapa final, estamos enfrentando o desafio interpretativo de escrever um relato significante e reflexivo do que tem sido um estudo emocionalmente intenso e inesperadamente difícil.

A dimensão emocional e estética do processo de pesquisa precisa ser reconhecida e incluída em dados observáveis, reflexivos e analíticos. (Ely, Friedman, Garner \& McCormack, 1991). De acordo com Woods (1996), professores no papel de artistas são "expressivos e emergentes, intuitivos e flexíveis, espontâneos e emocionais” (p. 6); estas qualidades também se aplicam claramente ao papel de um etnógrafo. Os pesquisadores do campo da etnografia precisam estar sintonizados e sensíveis aos instrumentos que utilizam para tornar familiar contextos "estranhos". Quando pesquisando um ambiente relativamente familiar de uma escola ou sala de aula de drama, o desafio é tentar perceber um mundo aparentemente comum de uma nova maneira, respondendo aos eventos da sala de aula e às vozes dos participantes com os sentidos aguçados de um artista. Ao examinar a nossa prática de drama educação através de uma lente etnográfica, nós precisamos expandir nossa consciência ao olhar "para" em vez de olhar "por" (Jackson in Eisner \& Peshkin, 1990:163). 
Ao analisar o “artístico” no ensino de Cecily O’Neill, Taylor (1995) define as qualidades que também são intrínsecas ao trabalho do etnógrafo. O’Neill está preocupada em dar aos participantes acesso a perspectivas e pontos de vista múltiplos, "para que se projetem inteiramente na situação" (p.20). De maneira similar, um etnógrafo busca compreender como os eventos e interações humanas são compreendidos por aqueles envolvidos, para acessar e "representar a realidade estudada em todos seus diferentes níveis de significado social, em sua completa plenitude” (Woods, 1996:5). No processo do drama, "os resultados não são pré-determinados mas sim descobertos em processo" (Taylor, 1995:13); isto equivale à abordagem de um etnógrafo que entra em campo sem uma hipótese pré-determinada e permite que as questões e temas da pesquisa emerjam do contexto.

O conceito de "pré-texto" para um drama educador e o conceito de “antecipação de problemas” - um termo usado por Malinowski (1922:9) para definir a atitude de um etnógrafo antes de entrar em campo, apresentam características similares. Assim como um "pré-texto" define expectativas, estabelece padrões e "dá origem a qualquer número de temas" gerando a ação dramática (Taylor, 1995:14), também a "antecipação de problemas" dá aos etnógrafos um senso de direção e um foco de enquadramento para guiar seu estudo de um grupo cultural e seu texto social. "Pré-texto" e "antecipação de problemas" facilitam uma abertura para os significados emergentes, de forma que as questões possam ser modificadas e outros temas possam surgir na medida em que o ensino procede. $\mathrm{Na}$ sessão de drama de Tiina Moore, a simples imagem que ela usou como pré-texto funcionou como um enquadramento evocativo que deflagrou o engajamento dos estudantes com o mistério central no coração do drama. Ela permaneceu um ponto de referência forte através das sessões do drama, e encorajou os participantes a explorar eventos passados e futuros e a gerar um texto dramático de múltiplas dimensões.

No coração do processo do drama está o fenômeno da "metaxis", definida por Boal (1995) como "o estado de pertencer completamente e simultaneamente a dois diferentes e autônomos mundos" (p.43). Isto relaciona-se diretamente com a atitude de um etnógrafo que precisa equilibrar os dois papéis de insider e outsider, atuando tanto como participante e como observador em um ambiente dinâmico. Assim como as qualidades pedagógicas e estéticas do drama dependem da tensão criativa e do jogo entre os mundos real e ficcional dentro do enquadramento do drama (Burton, 1991), também um etnógrafo precisa adotar tanto um "envolvimento pessoal profundo e uma medida de distanciamento" (Woods, 1977:261). Um aspecto da dimensão artística do trabalho de O’Neill é 
sua seleção deliberada de estratégias que possibilitarão aos participantes a experiência de engajamento e distanciamento na estrutura do drama (Taylor, 1995:25). Um etnógrafo "torna-se um instrumento de investigação ao jogar dois papéis - estando presente na situação e estando fora para observá-la” (Sherman \& Webb, 1988:86).

Em minha experiência, manter uma dupla perspectiva de envolvimento e distanciamento em relação à cultura sendo estudada é difícil e estressante. Em meu estudo do projeto de drama intercultural africano, meu papel ativo dentro do contexto me deu acesso ao mundo dos participantes e gerou uma grande quantidade de dados relacionados a suas experiências. Entretanto, meu engajamento com meu papel profissional dentro do projeto, e meu crescente envolvimento emocional com os participantes, tornou difícil manter uma atitude desapaixonada em relação ao objeto da pesquisa. Minhas próprias reações emocionais, incluindo às vezes sentimentos de frustração e desconforto, compõem uma parte integral dos dados na medida em que tentei monitorar os efeitos da tensão entre meu duplo papel como pesquisador e como participante.

Um projeto de pesquisa colaborativa pode prover os meios de equilibrar uma "percepção apaixonada de insider com uma desapaixonada de outsider" (Van Maanen, 1988:77). Estudos planejados de maneira que os eventos da sala de aula possam ser vistos tanto da perspectiva do insider como do outsider podem ser construídos (Smith \& Geoffrey, 1968). O projeto colaborativo do pré-texto assegurou que o professor-pesquisador pudesse atuar na perspectiva mais distanciada do co-pesquisador. Incluir o professor como parceiro integral na pesquisa pode evitar a solidão e o stress que surgem com a posição marginal do pesquisador dentro do contexto. Por outro lado, se o pesquisador pode dar conta da difícil posição simultânea de insider e outsider, com auto-controle entre familiaridade e estranhamento, ele pode gerar insights criativos no universo estudado (Hammersley \& Athinson, 1995:112).

$\mathrm{O}$ ato de construir um relato etnográfico, de contar a história do campo de trabalho, também envolve processos artísticos. Os dados precisam ser transformados em texto que seja expressivo e evocativo, que dê conta das qualidades emocionais e estéticas das experiências dos participantes e que envolva o leitor imaginativamente no desenrolar da história dos eventos do drama. O relato precisa ser reflexivo, isto é, incluir as próprias respostas emocionais do pesquisador aos eventos documentados. Crucialmente, é necessário prover o leitor com um relato interpretativo dos significados educacionais e culturais inerentes ao estudo, que tenham credibilidade. 
Em minha pesquisa anterior, eu usei formas narrativas para engajar o leitor no desenrolar de histórias de três processos de drama em sala de aula; vinhetas, bicos de pena, e sketches impressionistas foram usados para evocar as complexidades das experiências dos participantes dentro de cada contexto (Donelan, 1994). Eu relembro minha ansiedade que este trabalho pudesse ser dispensado, como trivial e carente de rigor de pesquisa, por uma audiência acadêmica. Em meus atuais projetos, parece apropriado construir relatórios de pesquisa que são dialógicos, pessoais, evocativos, metafóricos e que intercalam as vozes dos participantes em uma narrativa coletiva (Ely, 1996; Grumet, 1990). Eu estou interessada nas formas representacionais pós-modernas que usam uma ampla variedade de recursos artísticos para dar conta das múltiplas vozes, perspectivas fragmentadas e significados (Manning, 1995). Eu concordo com Richardson (1995) que "se nós queremos entender a mais profunda e a mais universal das experiências humanas, se nós queremos que nosso trabalho seja fiel à experiência viva das pessoas ... se nós queremos usar nossos privilégios e habilidades para fortalecer as pessoas que estudamos, então nós devemos valorizar a narrativa” (pp 218-219).

Sob meu ponto de vista, as qualidades da imaginação, criatividade, intuição, paixão e dedicação deveriam subsidiar tanto o nosso ensino de drama quanto nossa prática de pesquisa etnográfica. Apesar dos problemas e desafios inevitáveis que eu experimento em cada estudo, eu acredito no potencial da etnografia para prover insights únicos e valiosos sobre os complexos eventos culturais que caracterizam nosso trabalho como drama-educadores. Ao focalizarmos, como pesquisadores, o currículo de drama em seu contexto vivo, nós examinamos, criticamos, e expomos as qualidades estéticas e educacionais, e as suposições subjacentes ao nosso trabalho com os jovens.

\section{Nota}

Eu devo a Bruce Burton o título deste artigo. Ele usou a mesma frase como título do capítulo 3 de sua tese de Ph.D (1996).

\section{Referências Bibliográficas}

AGAR, M. "Literary journalism as ethnography". In J. Van Maanen (Ed.), Representation in Ethnography (pp 112-129). Thousand Oaks, CA: Sage, 1995. BOAL, A. The Rainbow of Desire. London: Routledge, 1995.

BURTON, B. The Act of Learning. Melbourne, AU: Longman Cheshire, 1991. 
DONELAN, K. Windows on the drama classroom: a collaborative, ethnographic approach to research. In J. Hughes (Ed.), Drama in Education: The State of the Art. New South Wales: Education Drama Association, pp 83-91, 1991.

DONELAN, K. The Teacher, the Students and the Drama: Using an Ethnographic Approach to Study Three Drama Classrooms". Unpublished Master's Thesis. University of Melbourne. Australia, 1994.

ELY, M., ANZUL, M., FRIEDMAN, T., GARNER, D. \& McCORMACK, A. Doing Qualitative Research: Circles within Circles. London: The Falmer Press, 1991. FLEMING, M. Starting Drama Teaching. London: David Fulton Publishers, 1994. GRUMET, M. "On daffoldils that come before the swallow dares". In E. Eisner \& A.Peshkin (Eds.), Qualitative Inquiry in Education: The Continuing Debate (pp 101-120). NY: Tachers College Press, 1990.

HAMMERSLEY, M. \& ATKINSON, P. Ethnography (2nd ed.). London: Routledge, 1995.

JACKSON, P. "Lookinf for trouble: On the place of the ordinary in educational studies”. In E. Eisner \& A. Peshkin (Eds.) Qualitative Inquiry in Education: The Continuing Debate (pp 153-166). NY: Teachers College Press, 1990.

MANNING, P. “The challenges of post modernism”. In J. Van Mannen (Ed.), Representation in Ethnography (pp 245-272). Thousand Oaks, CA: Sage, 1995.

MALINOWSKI, B. Argonauts of the Western Pacific. London: Routledge \& Kegan Paul, 1922.

O’NEILL, C. Drama Worlds. Portsmouth, NH: Heinemann, 1995.

O’TOOLE, J. The Process of Drama. NY: Routledge, 1992.

RICHARDSON, L. "Narrative and sociology". In J. Van Mannen (Ed.), Representation in Ethnography (pp 198-221). Thousand Oaks, CA: Sage, 1995.

SHERMAN, R. \& WEBB, R. (Eds.) Qualitative Research in Education: Focus and Methods. London: The Falmer Press, 1988.

SMITH, L. \& GEOFFREY, R. The Complexities of an Urban Classroom. NY: Holt, Reinhart \& Winston, 1968.

TAYLOR, P. (Ed.) Pre-Text and Storydrama: The Artistry of Cecily O'Neill and David Booth. NADIE Research Monograph No 1. Brisbane/AU: NADIE, 1995. VAN ALlSBURG, C. The Mysteries of Harris Burdick. London: Anderson Press, 1984.

VAN MAANEN, J. (Ed.) Representation in Ethnography. Thousand Oaks/CA: 1995. Tales of the Field. London:Sage, 1988.

WOODS, P. “The pupil's experience: A course text for Educational Studies Block II. In The process of Schooling. UK: Open University Press, 1977. Researching the Art of Teaching. London: Routledge, 1966.

WOLCOTT, H. The Art of Fieldwork. Walnut Creek/CA: Alta Mira Press, 1995. 


\section{NORMAS PARA PUBLICAÇÃo DE ARTIGOS}

1) Artigos - mínimo de 8 e máximo de 12 laudas. Resenhas de livros - mínimo de 3 e máximo de 4 laudas. Digitação em tipologia 12, Times New Roman, espaçamento normal, Word para Windows (ou compatível), limite de 5.700 caracteres com espaços por lauda;

2) Solicita-se clareza e objetividade nos títulos;

3) As notas devem ser formatadas em algarismos arábicos, apresentadas no rodapé da página. A bibliografia deve ser acrescentada imediatamente após as notas, obedecendo ao seguinte padrão: SOBRENOME, Nome, Título (tradutor), Local, Editora, Ano, páginas referidas (ex: 13-16). Para periódicos e jornais: SOBRENOME, Nome, Artigo/Reportagem, Periódico ou Jornal, n ${ }^{\circ}$ V (tradutor), Local, Editora, Ano ou Data, páginas referidas. Periódicos não devem ter títulos abreviados;

4) Para indicações de obras no corpo do texto ou final da citação: SOBRENOME, Ano: número da página. Para quaisquer outras normas, seguir o padrão ABNT vigente;

5) No corpo do texto, usar a primeira letra maiúscula e toda(s) a(s) palavra(s) em itálico para nomear títulos de peças, óperas, livros, títulos e obras em geral;

6) As colaborações devem incluir uma brevíssima apresentação do autor, visando situar o leitor, de no máximo 3 linhas;

7) À parte, o colaborador deve enviar uma autorização para publicação. Caso inclua fotos, desenhos ou outros materiais gráficos da autoria de terceiros, é indispensável o aceito dos mesmos assim como uma legenda de identificação; 
Urdimento

8) $\mathrm{O}$ conjunto destinado à publicação deve ser encaminhado em duas cópias impressas, uma em CD e outra para o e-mail urdimento@udesc.br aos cuidados da revista, até o prazo do fechamento.

Endereço para correspondência e envio de colaborações:

\section{Revista Urdimento}

Programa de Pós-Graduação em Teatro - UDESC

Av. Madre Benvenuta, 1.907 - Itacorubi

88.035-001 - Florianópolis - SC

E-mail: urdimento@udesc.br 
Realização:

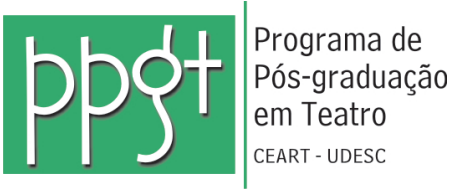

Programa de Pós-Graduação em Teatro

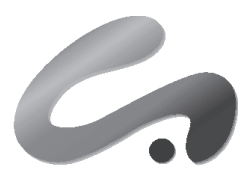

CEART

Centro de Artes 
Diagramação Editorial

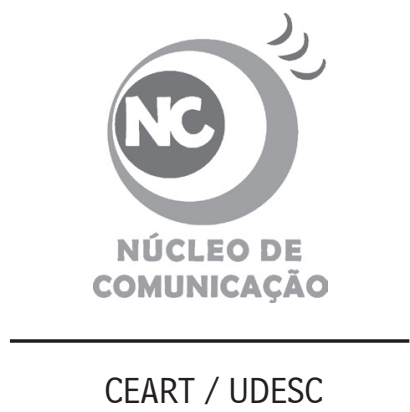

Este projeto editorial foi criado eletronicamente utilizando o software Adobe In Design CS3. As famílias tipográficas Bell MT e BellCent são utilizadas em toda esta revista. 